Check for updates

Cite this: RSC Adv., 2017, 7, 39314

\title{
Quantification of ionic organo(fluoro)phosphates in decomposed lithium battery electrolytes
}

\author{
Jennifer Menzel, ${ }^{a}$ Hannah Schultz, ${ }^{a}$ Vadim Kraft, ${ }^{a}$ Juan Pablo Badillo, ${ }^{a}$ Martin Winter ${ }^{\text {ab }}$ \\ and Sascha Nowak (iD *a
}

A method for the separation, identification and quantification of the ionic decomposition products of LiPF 6 based organic electrolytes was developed. It employed the simultaneous coupling of two-dimensional ion chromatography (2D IC) with electrospray-ionization mass spectrometry (ESI-MS) and with inductively coupled plasma-mass spectrometry (ICP-MS). The electrolyte under investigation was a commercially available electrolyte by BASF, consisting of $1 \mathrm{~mol} \mathrm{~L}^{-1} \mathrm{LiPF}_{6}$ in a mixture of one linear and one cyclic organic carbonate (50:50 wt\%). The quantification was based on the use of a structurally similar compound as calibration standard for the ICP-MS measurement, while the identification was carried out with ESI-MS. Several organo(fluoro)phosphate species were successfully separated and quantified. Since these species show a high structural similarity to the warfare agent sarin, their investigation is of special interest with regard to their potential toxicity. Additionally, a quantification study of an electrolyte extracted from a cycled lithium metal cell was carried out.

Received 7th July 2017

Accepted 5th August 2017

DOI: $10.1039 / \mathrm{c} 7 \mathrm{ra07486g}$

rsc.li/rsc-advances electrolyte is a major drawback for a long-term battery cell performance. Due to its hygroscopicity, $\mathrm{LiPF}_{6}$ always contains small amounts of water, which is known to accelerate the decomposition process of $\mathrm{LiPF}_{6}$. In the organic carbonate solvents, $\mathrm{LiPF}_{6}$ stands in equilibrium with $\mathrm{LiF}$ and $\mathrm{PF}_{5} \cdot{ }^{19,20} \mathrm{In}$ presence of protic impurities like water, $\mathrm{PF}_{5}$ reacts to inorganic phosphates under release of $\mathrm{HF}^{21}$ At elevated temperatures beginning already with $40{ }^{\circ} \mathrm{C}$ and at high positive electrode potentials $>4.9 \mathrm{~V} \mathrm{Li} / \mathrm{Li}^{+}$, the phosphates undergo reactions with the carbonates. ${ }^{22-24}$ Through these reactions $\mathrm{CO}_{2}$ gas and organophosphates dissolved in the electrolyte are formed. These compounds are known to impair the LIB performance ${ }^{25}$ and furthermore some organophosphates have structural similarities with nerve agents like $\operatorname{sarin}^{26}$ and are potentially toxic. $^{27-31}$ This toxicity is due to the inhibition of the mammal enzyme acetylcholinesterase $\mathrm{e}^{26,30,32}$

Most of the previous analytical studies were focused on the identification of possible decomposition products. The first studies were carried out with $\mathrm{DSC}^{33,34}$ and $\mathrm{TGA}^{35}$ in order to describe the thermal stability of the electrolyte. The organophosphates previously reported in literature were detected with numerous analytical methods. By using nuclear magnetic resonance (NMR), ${ }^{8,36-40}$ different ionic and non-ionic main compounds were identified. Yet, NMR due to the high limit of detection low concentrations of organophosphates were not detected. High resolution-electrospray ionization-mass spectrometry (HR-ESI-MS) in the positive mode, ${ }^{7,9,21,41-43}$ liquid chromatography-based methods $\mathrm{s}^{30,44-46}$ and gas chromatographymass spectrometry (GC-MS) were applied to find and identify neutral organophosphates ${ }^{7,9,41-43,47}$ while ion chromatography-
${ }^{a}$ University of Münster, MEET Battery Research Center, Institute of Physical Chemistry, Corrensstraße 46, 48149 Münster, Germany. E-mail: sascha.nowak@uni-muenster.de

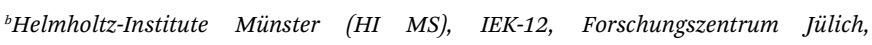
Corrensstraße 46, 48149 Münster, Germany 
electrospray ionization-mass spectroscopy with product ion scan (IC-ESI-MS/MS) $)^{22,48,49}$ proved to be highly useful for the identification of ionic compounds. The attempts mainly covered the quantification of HF by spectroscopic ellipsometry ${ }^{50,51}$ as well as the educt $\mathrm{LiPF}_{6}$. Further fluoride quantification was done by capillary electrophoresis (CE) and IC with conductivity detection and a fluoride sensitive electrode. ${ }^{21,24,52-54}$ So far, the quantification of the organophosphates was difficult due to the absence of analytical standards. Only two substances, dimethyl fluorophosphate (DMFP) and diethyl fluorophosphate (DEFP) were successfully quantified by GC-MS ${ }^{47}$ with synthesized calibration standards. However, recently, approaches with liquid chromatography-tandem mass spectrometry were carried out. $^{52,55}$ For the ionic compounds, a method was published which used a relative quantification with an internal standard with IC-ESI-MS ${ }^{24}$ in order to monitor the degradation process.

Nevertheless, an absolute quantification of the organophosphates can be achieved with ICP-MS with a phosphorous containing calibration standard. Therefore, it is crucial that the individual species are well separated before they are transferred into the ICP-MS. In this work a newly developed method for the quantification of the organo(fluoro)phosphates is presented. An IC/IC system as presented by Kraft et $a l^{.99}$ has been modified to fulfill the needs of the hyphenation to the ICP-MS and a simultaneous hyphenation to the ESI-MS was applied.

\section{Material and methods}

\subsection{Chemicals}

Battery grade electrolyte LP30 (50/50 wt\% ethylene carbonate (EC)/dimethyl carbonate (DMC) and $\left.1 \mathrm{M} \mathrm{LiPF}_{6}\right)$, and LP50 (50/50 wt\% ethylene carbonate (EC)/ethyl methyl carbonate (EMC) and $1 \mathrm{M} \mathrm{LiPF}_{6}$ ) SelectiLyte ${ }^{\mathrm{TM}}$ were purchased from BASF (Ludwigshafen, Germany). Deionized water from a Millipore Milli-Q water system with a LC-PAK cartridge (Bedford, USA) was used as contaminant and for the preparation of eluents and internal standard. Sodium carbonate (Certipur), sodium bicarbonate (for analysis) and sodium hydroxide solution (30\%, Suprapur) were purchased from Merck (Darmstadt, Germany). Acetonitrile (HPLC gradient grade) for sample dilution and organic elution gradient was obtained from VWR (Bruchsal, Germany). As internal standard tellurium ICP-MS Standard in $2-3 \% \mathrm{HNO}_{3}$ (Certipur, Merck, Darmstadt, Germany) and for the calibration dibutyl phosphate $(97.0 \%$ purity, Sigma-Aldrich, Steinheim, Germany) were applied.

\subsection{IC/IC conditions}

For the two-dimensional anion exchange chromatography, devices from Metrohm (Herisau, Switzerland) were used. The samples were introduced into the system with an 889 IC sample center. The measurements on the first dimension were carried out with an 850 Professional IC equipped with a conductivity detection unit. The second dimension was run with two 872 extension modules containing a pump, a chemical suppressor and a $\mathrm{CO}_{2}$ suppressor. For the detection a second conductivity detector was used. All instruments were operated with the

software MagIC Net 3.0 (Metrohm, Herisau, Switzerland). On the first dimension a $\mathrm{Na}_{2} \mathrm{CO}_{3} / \mathrm{NaHCO}_{3}$ eluent $\left(1.8 / 1.7 \mathrm{mmol} \mathrm{L}{ }^{-1}\right)$ was used with a gradient step. From 9 to 16 minutes $50 \%$ of acetonitrile was added while the carbonate concentration remained unchanged. The second dimension was run isocratically with an eluent out of $10 \mathrm{mM} \mathrm{NaOH}$.

Further conditions can be found in Table 1.

\subsection{ICP-MS conditions}

All ICP-MS measurements were carried out with an Agilent $7700 \times$ Series ICP-MS (Agilent Technologies, Santa Clara, USA). The instrument was operated with the software Mass Hunter A.01.02 from Agilent Technologies (Santa Clara, USA). The internal standard (Te ICP-Standard (984 $\pm 4 \mathrm{mg} \mathrm{kg}^{-1}$ ), diluted by factor 10000 in deionized water) was pumped with a flow of $1.3 \mathrm{~mL} \mathrm{~min}^{-1}$ against counter pressure. All further conditions are given in Table 2 .

\subsection{ESI-MS conditions}

For the ESI-MS measurements a triple quadrupole/linear ion trap instrument 3200QTrap (AB Sciex, Framingham, USA) was used. The instrument was controlled with the software Analyst 1.5.2 by AB Sciex (Framingham, USA). All other conditions can be found in Table 3 .

\subsection{Measurement setup}

The two mass spectrometers were coupled simultaneously after the IC. The setup was used as shown in Fig. 1. Therefore, a split into both devices was applied after the second detector in the

Table 1 IC parameters

\section{Instrument}

Eluent 1

Column 1

Guard column 1

Flow rate 1

Preconcentration column

Eluent 2

Column 2

Guard column 2

Flow rate 2

Column temperature

Sample processor

Injection volume
Metrohm 850 Professional IC

$1.80 \mathrm{mM} \mathrm{Na}_{2} \mathrm{CO}_{3}, 1.70 \mathrm{mM} \mathrm{NaHCO}$ Metrosep A supp $4250 \times 4.0$

Metrosep A supp 4/5 guard/4.0

$1.0 \mathrm{~mL} \mathrm{~min}^{-1}$

Metrosep A PCC 1/4.0

$10 \mathrm{mM} \mathrm{NaOH}$

Metrosep A supp $10250 \times 4.0 \mathrm{~mm}$

Metrosep A supp 10 guard $/ 4.0 \mathrm{~mm}$

$1.0 \mathrm{~mL} \mathrm{~min}^{-1}$

$40{ }^{\circ} \mathrm{C}$

Metrohm 889 sample center

$10 \mu \mathrm{L}$

Table 2 ICP-MS parameters

Instrument RF power

Carrier gas flow

Torch

Nebulizer

Spray chamber temperature

Sampling depth

Integration time

Split
Agilent 7700 Series ICP-MS

$1550 \mathrm{~W}$

$1.05 \mathrm{~L} \mathrm{~min}^{-1}$

Quartz, $1.8 \mathrm{~mm}$ i.d.

Micro mist

$2{ }^{\circ} \mathrm{C}$

$8.0 \mathrm{~mm}$

$0.1 \mathrm{~s}$

$1: 1$ 
Table 3 ESI-MS parameters

\section{Instrument}

Mode

Mass range

Integration time

Ion spray voltage

Curtain gas

Ion source gas 1

Ion source gas 2

Temperature

Declustering potential

Entrance potential
AB Sciex 3200 QTrap

Negative, full scan

$\mathrm{m} / \mathrm{z}$ 50-250

$1 \mathrm{~s}$

$-4250 \mathrm{~V}$

$30 \mathrm{psi}$

$35 \mathrm{psi}$

35 psi

$450{ }^{\circ} \mathrm{C}$

$-20 \mathrm{~V}$

$-8 \mathrm{~V}$
IC. Due to tubing and pump speed, the ESI-MS was operated with a flow of $0.2 \mathrm{~mL} \mathrm{~min}^{-1}$. The tube to the ICP-MS was then led into a four-way connector. The internal standard was added at this point with a flow rate of $1.3 \mathrm{~mL} \mathrm{~min}^{-1}$ (measured without counter pressure). Also connected to this four way connector were the sample introduction and the split tube, which were pumped by the peristaltic pump of the Agilent 7700 Series ICPMS at a pump rate of $0.5 \mathrm{rps}$, resulting in a $1: 1$ split.

\subsection{Sample preparation}

In order to quantitatively study the influence of moisture on the aging of $\mathrm{LiPF}_{6}$ based electrolytes, the samples aging was carried out after addition of water. For simplicity reasons, the electrolyte LP30 was chosen as it produces only organo(fluoro)phosphates with methyl groups. These species can be fully separated while the aging products of LP50 which also contains ethyl side chains undergo group separation. ${ }^{49}$ The formation reactions for the homologous species with methyl and ethyl side chains follow the same pathways and hence do not play an influential role during the reaction. Therefore, LP30 can be considered as a simplified system for LP50 which was applied during the initial method development.

The aging of $\mathrm{LiPF}_{6}$ based electrolyte is initiated by traces of water in the electrolyte. The water reacts with the pentafluorophosphate which is in a constant equilibrium with lithium fluoride and hexafluorophosphate. A temperature of $95{ }^{\circ} \mathrm{C}$ was chosen to age the samples within short times. In the quantification part the samples were prepared with different amounts of water to gain information about the kinetics of the organo(fluoro)phosphate formation.

Different amounts of water were added to the electrolyte to a maximum of $2.5 \mathrm{vol} \%$. A minimum of three identical samples per amount of water was prepared. The samples were prepared in a dry room (dew point: $\left.-50{ }^{\circ} \mathrm{C}\right)$. The electrolyte $(1 \mathrm{~mL}$ each) was stored in gas-tight stainless steel containers (containers: workshop, University of Münster, cap and perfluoralkoxy (PFA) sealing by Swagelok, Solon, USA) at $95^{\circ} \mathrm{C}$ for $24 \mathrm{~h}$.

After aging, the samples were diluted in acetonitrile by a factor of 100 .

For method development, samples with 0.8 vol\% of water were aged at $95{ }^{\circ} \mathrm{C}$ for 29 days.

The electrolyte from the cycled cells was extracted by centrifugation of the separator for 15 minutes at $8.5 \mathrm{rpm}$. The

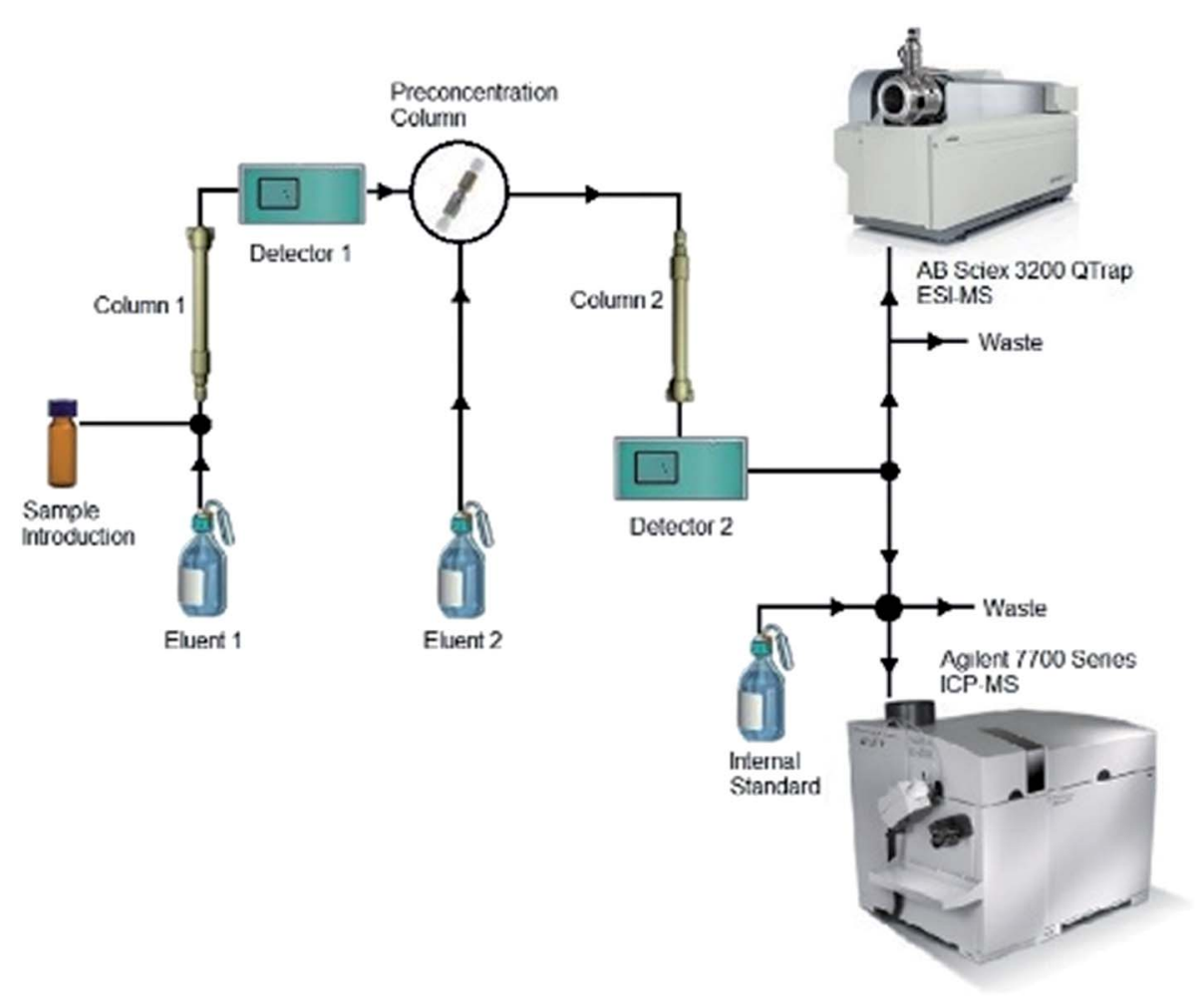

Fig. 1 Experimental setup. The two-dimensional IC is hyphenated to the ESI-MS and the ICP-MS with a three way split. The internal standard is added to the ICP-MS after the initial split. 
samples were subsequently diluted in acetonitrile by a factor of 10 .

The calibration standards were prepared by dilution of dibutyl phosphate in acetonitrile in the range from $0.5 \mathrm{mg} \mathrm{kg}^{-1}$ to $100 \mathrm{mg} \mathrm{kg}^{-1}$.

\subsection{Cell assembly and cycling procedure}

For constant current cycling, coin cells with lithium metal as anode and $\mathrm{LiNi}_{0.5} \mathrm{Mn}_{1.5} \mathrm{O}_{4}$ (LNMO) as cathode were assembled in a dry room (dew point: $-50{ }^{\circ} \mathrm{C}$ ). The LNMO cathodes were prepared in-house. They consist out of $86 \mathrm{wt} \%$ of LNMO (Customcells), of $9 \mathrm{wt} \%$ conductive additive Super C65 (TIMCAL) and of $5 \mathrm{wt} \%$ polyvinyllidene difluoride (Solvay). The components were solved in anhydrous $N$-methyl-2-pyrrolidone (Sigma Aldrich) before coating on an aluminum foil. They were then dried at $70{ }^{\circ} \mathrm{C}$, pressed and afterwards dried again under vacuum at $120{ }^{\circ} \mathrm{C}$. The mass loading of the active material was $2 \mathrm{mg} \mathrm{cm}^{-2}$ and the diameter of the electrodes was $12 \mathrm{~mm}$. The diameter of the lithium metal anode was $15 \mathrm{~mm}$. The separator was prepared out of 5 layers of Freudenberg 2190 and one layer of Celgard 2500 (Celgard LLC, Charlotte, NC), the diameter was $17 \mathrm{~mm}$. The separator was orientated in a way that the Celgard side faced the cathode. Here, as electrolyte LP50 $(150 \mu \mathrm{L})$ was applied.

The cells were cycled in a Maccor series 4000 battery test system (Maccor Inc.). Three formation cycles were carried out with a charge and discharge current of $0.0678 \mathrm{~mA}$ between an upper cut-off voltage of $4.9 \mathrm{~V}$ and a lower cut-off voltage of $3.5 \mathrm{~V}$. Then the cells were charged with $0.339 \mathrm{~mA}$ to $5.5 \mathrm{~V}$ and held there for $10 \mathrm{~h}$. Finally, the cells were again discharged to $3.5 \mathrm{~V}$.

\section{Results and discussion}

\subsection{Separation}

In the first dimension of the IC, the organo(fluoro)phosphates were insufficiently separated from each other and appeared as a shoulder on the fluoride signal as shown in Fig. 2. A separation could be possible after a long elution time on a column with hydrophobic character, enabling the interaction with alkyl groups of the organo(fluoro)phosphates. The maximum content of organic solvents for the hydrophobic column was limited to $10 \%$, preventing the elution of the hexafluorophosphate. $\mathrm{PF}_{6}{ }^{-}$ was only eluted after the application of an organic gradient with high contents. However, the addition of organic compounds would further make the plasma instable or extinguish it. Therefore, the method of choice was the application of a twodimensional chromatography using the cutting of the fraction with the organo(fluoro)phosphates from the first dimension and their transfer onto the second column.

In the second dimension, the fluoride signal still overlapped with three organo(fluoro)phosphate signals in the conductivity detector (Fig. 3). In the phosphorous selective detection in the ICP-MS (Fig. 4) it is shown that there were five baseline separated signals. Three of these signals were eluted together with the fluoride and could therefore not be detected in the conductivity detector. The other two signals were also visible in

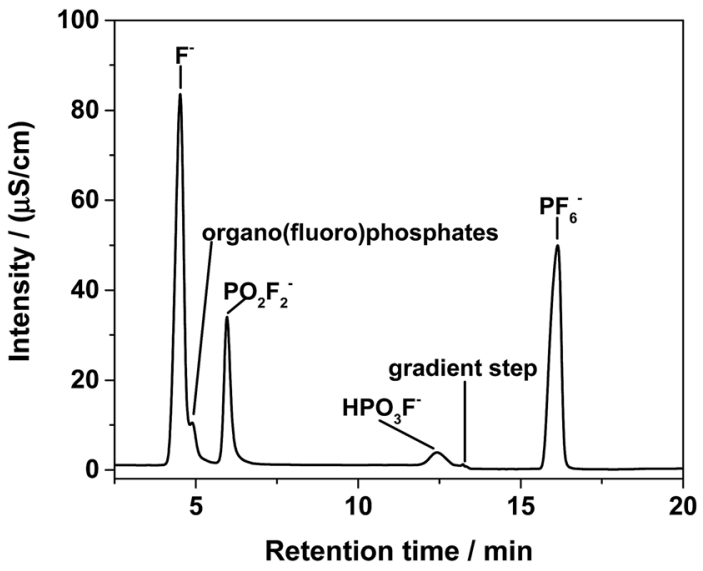

Fig. 2 Ion chromatogram by conductivity detection of LP30 after addition of 0.8 vol\% of water, aged at $95^{\circ} \mathrm{C}$ for 29 days, $1^{\text {st }}$ dimension. The precursor hexafluorophosphate and its decomposition products including organo(fluoro)phosphates were detected. The organo (fluoro)phosphates were insufficiently separated from the fluoride signal.

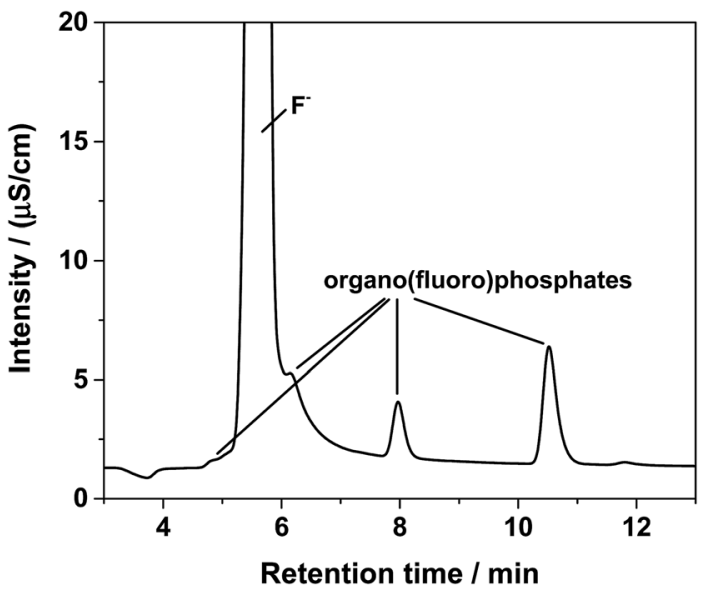

Fig. 3 Ion chromatogram by conductivity detection of LP30 after addition of 0.8 vol\% of water, aged at $95^{\circ} \mathrm{C}$ for 29 days, $2^{\text {nd }}$ dimension.

the conductivity measurement. They were therefore phosphorous containing species.

\subsection{Identification}

The signals were identified with ESI-MS. The matching mass chromatogram is shown in Fig. 5. The obtained masses for the five signals were assigned to the organo(fluoro)phosphate species that were already identified by Kraft et al. ${ }^{\mathbf{4 9}}$ The substances which were found in amounts > LOQ (limit of quantification) were methyl fluorophosphate (MFP) 1, ethylene phosphate (EP) 2, dimethyl phosphate (DMP) 3, methoxyethyl fluorophosphate (MEFP) 4 and methoxyethyl methyl phosphate (MEMP) 5. The structures are given in Table 4 .

LP50 was used as electrolyte in the electrochemical investigations for the following reasons: the wetting behavior of LP30 with separators, which enable a good electrolyte recovery by centrifugation, was very poor, which resulted in inefficient 


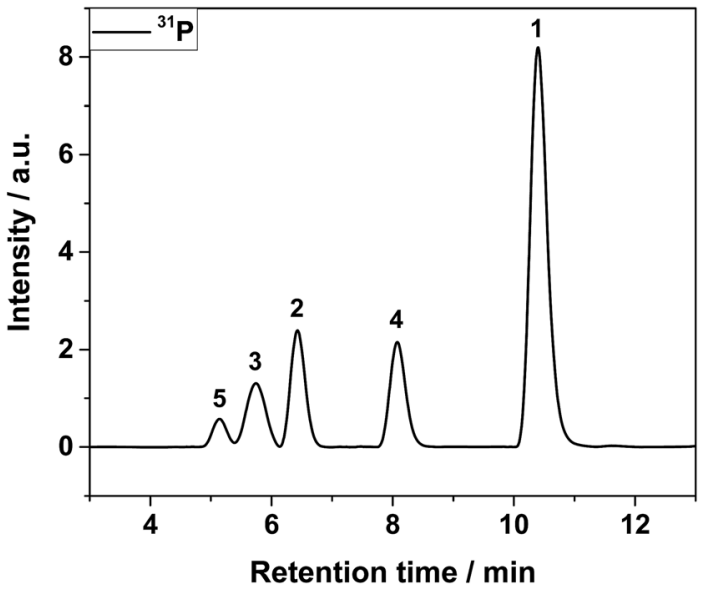

Fig. 4 ICP-MS chromatogram after 2nd dimension IC of LP30 after addition of 0.8 vol\% of water, aged at $95^{\circ} \mathrm{C}$ for 29 day.

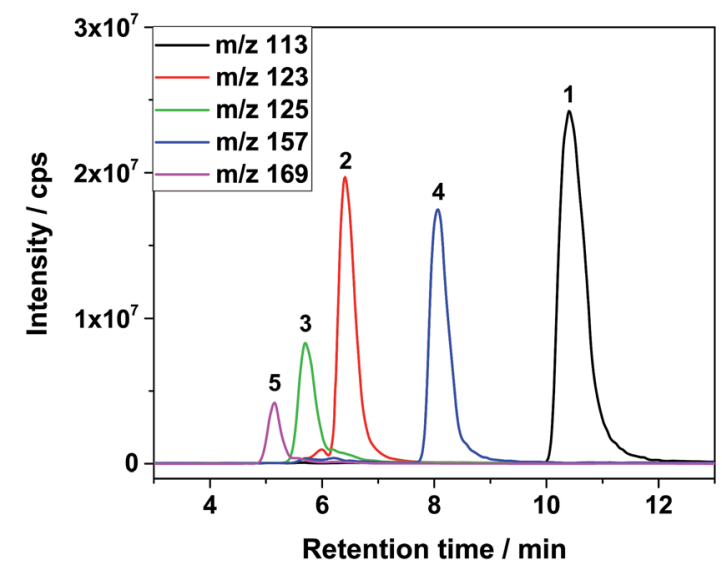

Fig. 5 ESI-MS mass chromatogram after 2nd dimension IC of LP30 after addition of 0.8 vol\% of water, aged at $95^{\circ} \mathrm{C}$ for 29 days.

charge/discharge cycling of the cell. LP50 contains ethyl methyl carbonate (EMC) instead of DMC. Therefore, the decomposition products will have both, methyl and ethyl side chains instead of methyl side chains only. An overall overview about the possible decompositions products can be achieved. The individual species with different side chains were not separable by the applied method. The organo(fluoro)phosphates hence underwent a group separation. ${ }^{49}$ The 2D-IC-ICP chromatogram alongside with the ESI-chromatogram are shown in Fig. 6.

The additional species that differed from LP30 decomposition products are given in Table 5. MEFP and MEMP as well as their homologues with ethyl side chain have not been detected. The retention times were higher compared to the chromatogram in Fig. 4 because for this measurement a new A sup 10 column was applied which still had a higher capacity.

\subsection{Development of a method for the quantification of organo(fluoro)phosphates}

For the quantification of the organo(fluoro)phosphates it was necessary to have a standard which was treatable with the same separation method as the analytes. Therefore, it was essential to find species that eluted from the first separation column without organic modifier with a short retention time. The standard also needed to be eluted from the second column with the same aqueous sodium hydroxide solution as the analytes with a short retention time and in a sharp signal. Therefore, three phosphorus containing substances were investigated. The hexafluorophosphate salt, i.e., the precursor for the organo (fluoro)phosphates was not among the candidates for the standards because it eluted on the first column only under application of an organic gradient. This was already known from the first dimension separation of the electrolyte (Fig. 2). Phosphate was investigated as the first candidate for the calibration standard. It showed the same behavior as hexafluorophosphate and only eluted after application of an organic gradient. The other candidates, monofluorophosphate and dibutyl phosphate showed similar retention behavior on both columns. Dibutyl phosphate was chosen as calibration standard due to the higher structural similarity to the organo(fluoro) phosphates. Further, there was also a fluoride signal visible in the chromatograms of monofluorophosphate. This was attributed to hydrolysis of the substance.

A calibration with dibutyl phosphate using six data points resulted in a straight line graph with the slope of $6.54 \pm 0.08$ and the intercept of $-0.8 \pm 0.2$. The $R^{2}$ value was 0.9992 which proved a strong correlation between the signal and the concentration. The limits of quantification and detection were determined graphically from the peak height and noise width. The LOQ was $0.4 \mathrm{mg} \mathrm{L}^{-1}\left(0.01 \mathrm{mmol} \mathrm{L}^{-1}\right)$ while the LOD was $0.12 \mathrm{mg} \mathrm{L}^{-1}\left(3.8 \times 10^{-3} \mathrm{mmol} \mathrm{L}^{-1}\right)$ both relating to phosphorus. These limits were still low considering that the quantification was applied after a separation instead of measuring the total phosphorous amount.

An internal standard of $100 \mathrm{ppb}$ tellurium which was constantly injected into the system was used in order to monitor the plasma stability.

\subsection{Quantification}

For quantification, samples of LP30 with different amounts of water, which had been aged under the same conditions, have been analyzed with the previously described method. The quantification results are shown in Fig. 7. The errors marked with error bars were the standard deviations from the three samples, which were used for each data point. The error for the single measurements was $1.5 \%$ and thus negligible compared to the standard deviations, which resulted from non-uniform aging of the samples. The standard deviations could go up to $10 \%$ of the measured mean value.

From Fig. 7, it can be seen that without water addition there were no decomposition products observed after one day of thermal aging. In order to gain information about the reaction mechanisms in the electrolyte without water addition, the electrolyte from a cycled cell at elevated cut-off voltage was investigated.

The chromatogram is shown in Fig. 6 and the corresponding quantification results are given in Table 6 . The results show that 
Table 4 Structures of the organo(fluoro)phosphates from the thermal aging of LP30<smiles>COP(=O)([O-])F</smiles><smiles>O=P1([O-])OCCO1</smiles>

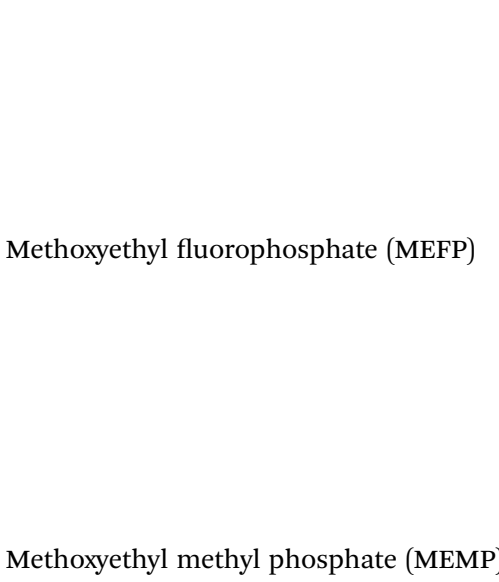

169<smiles>COP(=O)(O)OC</smiles>
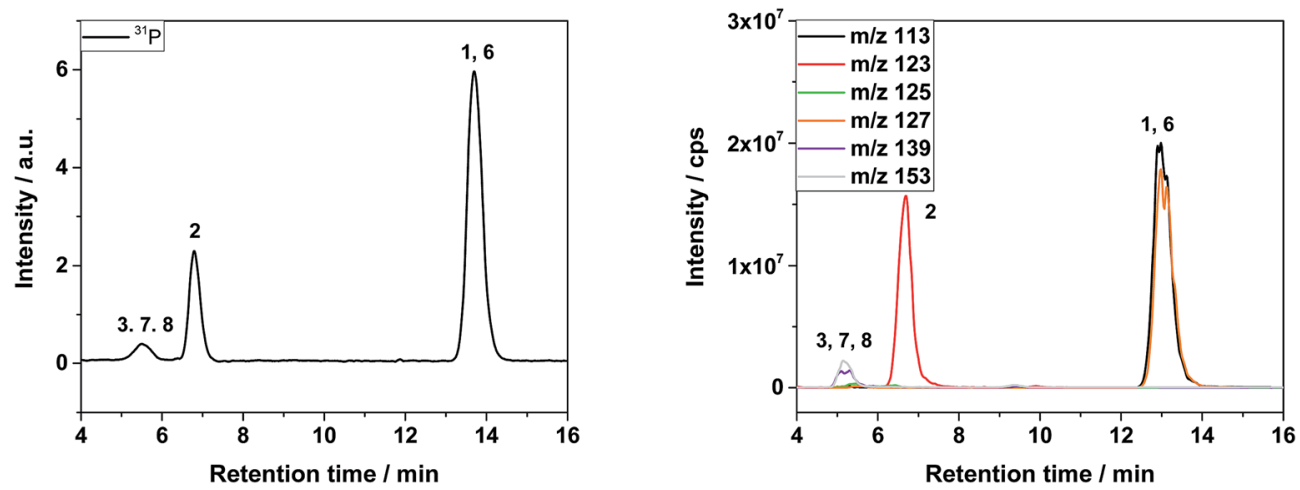

Fig. 6 ICP-MS chromatogram and ESI-chromatogram of LP50 from aged Li metal/LNMO coin cells. 
Table 5 Structure of the organo(fluoro)phosphates from the cyclic aging of LP50

\begin{tabular}{|c|c|c|c|}
\hline Number & Name & $m / z$ & Chemical structure \\
\hline 6 & Ethyl fluorophosphate (DFP) & 127 & \\
\hline 7 & Ethyl methyl phosphate (MEP) & 139 & \\
\hline 8 & Diethyl phosphate (DEP) & 153 & \\
\hline
\end{tabular}

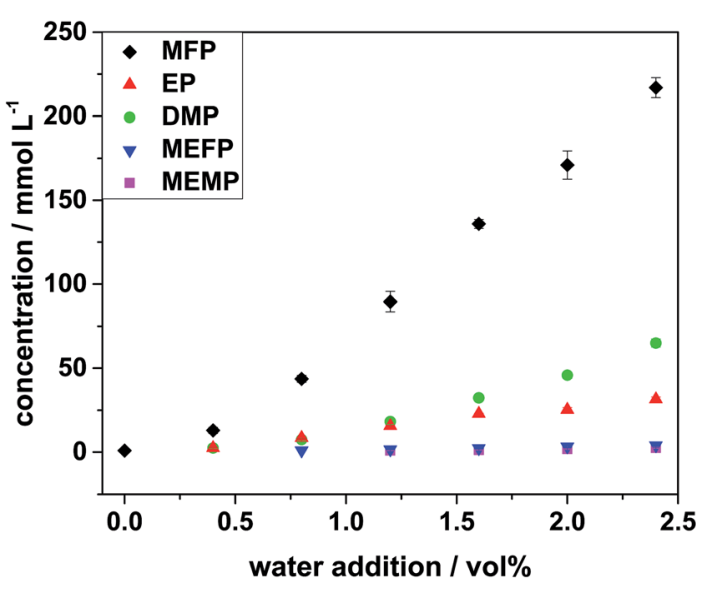

Fig. 7 Quantification results for the five organo(fluoro)phosphates after aging for $24 \mathrm{~h}$ at $95{ }^{\circ} \mathrm{C}$ with addition of different amounts of water.

the main aging product in the cycling aging was MFP, just as it was in the aging with water addition. Yet, with $3.7 \pm$ $0.2 \mathrm{mmol} \mathrm{L}^{-1}$ the total amount was low compared to the yields in the aging with water. Upon addition of only $0.4 \mathrm{vol} \%$ of water

Table 6 Quantification results for the organo(fluoro) phosphates from the electrolyte of the cycled cells

\begin{tabular}{llll}
\hline Species & MFP + DFP & EP & DMP + EMP + DEP \\
\hline Amount $/ \mathrm{mmol} \mathrm{L}^{-1}$ & $3.7 \pm 0.2$ & $0.93 \pm 0.06$ & $0.26 \pm 0.04$
\end{tabular}

the amount of MFP was at $13 \pm 1 \mathrm{mmol} \mathrm{L}^{-1}$ after $24 \mathrm{~h}$ of thermal aging. This shows that the thermal aging at $95^{\circ} \mathrm{C}$ with water was highly aggressive compared to cyclic aging.

The second most abundant species was EP. Comparison with the thermally aged samples shows that this was not in accordance with the findings in the samples with water addition. In this case DMP occured in higher concentrations than EP did. This phenomenon was attributed to the decomposition of $\mathrm{PF}_{6}{ }^{-}$ to less fluorinated phosphates. They are considered precursors for the formation of the organo(fluoro)phosphates. The more complex organo(fluoro)phosphates MEFP and MEMP were only formed after high amounts of water addition. They were formed as a concurrence reaction to the ring closure of the EP formation since both reactions have fluoroethyl phosphate as a precursor. The results showed that the reaction of fluoroethyl phosphate with water, resulting in EP formation was faster than the reaction with DMC.

These results lead to the conclusion that the organo(fluoro) phosphate formation kinetics depend on the aging pathway. Hence, different pathways were favored in thermal and cyclic aging. Yet, the investigation of the mechanism was not feasible by IC based measurements alone and require theoretical calculations of the influence of thermal and electrochemical influences of the reaction constants.

Regarding the influences of the water addition the amount of decomposition products increased with the amount of added water. The increase of the amounts of the organo(fluoro)phosphates was almost linear with the higher water addition. Only the first two measurement points for each organo(fluoro)phosphate did not match this trend. This was also observed regarding the accumulated amounts of the organo(fluoro) 


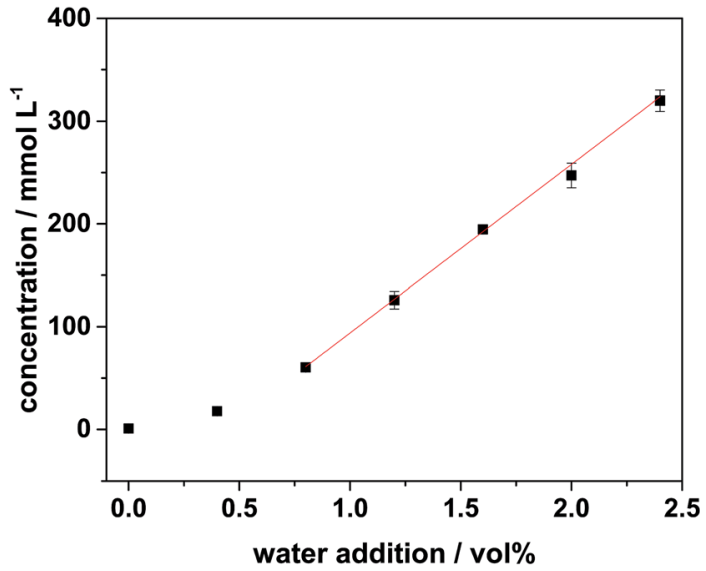

Fig. 8 Accumulated quantification for the organo(fluoro)phosphates after aging for $24 \mathrm{~h}$ at $95{ }^{\circ} \mathrm{C}$ with addition of different amounts of water.

phosphates. They are shown in Fig. 8. This effect could be caused by reactions that could not be monitored in this method. These reactions are hydrolysis steps of hexafluorophosphate, which lead to the formation of difluorophosphate and monofluorophosphate. These species were also precursors for the organo(fluoro)phosphate formation. They consumed small amounts of water and only with an excess of water the organo(fluoro)phosphate formation took place. Due to the twodimensional approach, they were not visible in the ICP-MS chromatogram, but they have always been observed in the first dimension after conductivity detection. They were thus still present after the formation of the organo(fluoro)phosphates and lead to a consumption of water which could not be explained by organo(fluoro)phosphate formation alone. Furthermore, there existed also reaction pathways which lead to the formation of nonionic organo(fluoro)phosphates which were not accessible with ion chromatography.

It was clearly visible that MFP was formed in a high excess compared to the other organo(fluoro)phosphates. At an addition of $2.0 \mathrm{vol} \%$ of water $171 \mathrm{mmol} \mathrm{L}^{-1}$ MFP were detected while the amount of EP $\left(25 \mathrm{mmol} \mathrm{L}^{-1}\right)$ was only $15 \%$ of it. MEFP and MEMP were even less with only 1 and $2 \%$ compared with MFP. DMP was the second most abundant organo(fluoro)phosphate with $27 \%$ of the amount of MFP after addition of $2.0 \mathrm{vol} \%$ of water. According to Kraft et al. ${ }^{49}$ DMP was formed from an alkoxylation reaction of MFP. Therefore, it was only formed if MFP has been formed before. The significantly higher amount of MFP shows that the formation of DMP from MFP was slower than the formation of MFP.

Furthermore, the more complex organo(fluoro)phosphates like MEFP and MEMP were only formed upon high amounts of water addition. In order to make their quantification more visible, Fig. 9 gives a zoom into the amounts to which they are formed. They have structural similarities to EP and it was suggested by Kraft et $a l .{ }^{49}$ that they were formed as a concurrence reaction. The current results show that the formation of EP was favored compared to the formation of MEFP and MEMP. In order to form EP, the precursor fluoroethyl phosphate reacted

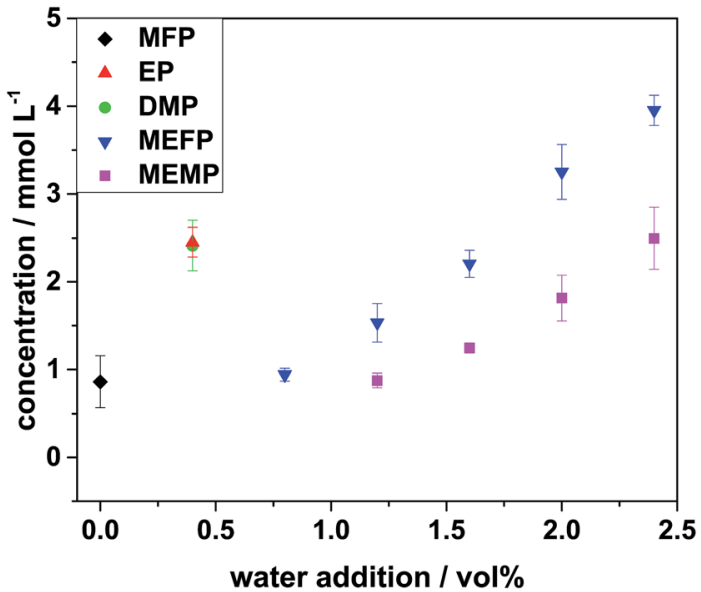

Fig. 9 Zoom-in from Fig. 6 to the lowest amount organo(fluoro) phosphates MEFP and MEMP.

with water while MEFP and MEMP were formed by a reaction with DMP. From the results it can be concluded that the reaction with water was faster than the reaction with DMP so that MEFP and MEMP were only formed if fluoroethyl phosphate existed in large quantities.

\section{Conclusion}

A new method for the quantification of ionic organo(fluoro) phosphates in $\mathrm{LiPF}_{6}$-based LIB electrolytes was developed. The organo(fluoro)phosphates were generated by thermal aging at $95{ }^{\circ} \mathrm{C}$ for $24 \mathrm{~h}$ with addition of 0 to $2.5 \mathrm{vol} \%$ of water. The method uses a simultaneous hyphenation of a two dimensional heartcut ion chromatography with an ESI-MS and an ICP-MS. This enables the simultaneous identification and quantification of the different organo(fluoro)phosphate species. The quantification was realized by using dibutylphosphate as a structurally similar phosphorous containing calibration standard. The quantification of these substances enables the investigation of influences on the degradation of $\mathrm{LiPF}_{6}$ in the LIB electrolyte. It is the first method which is able to compare the amounts of different ionic organo(fluoro)phosphate species by means of quantification.

In the current study the influence on the amount of water in the degradation process was investigated. The water amount was found to have a strong effect on the formation of the organo(fluoro)phosphates. The comparison of the amounts of the individual organo(fluoro)phosphates gives an insight into the relative formation rate of the substances. It shows that MFP is formed in the highest amount followed by DMP and EP. The rise of their amount shows a linear behavior. Yet, this is not true for low water amounts. This phenomenon is attributed to the decomposition of $\mathrm{PF}_{6}{ }^{-}$to less fluorinated phosphates. They are precursors for the formation of the organo(fluoro)phosphates. The more complex organo(fluoro)phosphates MEFP and MEMP are only formed after high amounts of water addition as they compete with EP for a common precursor. 
As a first attempt of quantification of ionic organo(fluoro) phosphates in battery systems, a quantification from cycled Limetal cells was carried out. It shows that MEFP and MEMP are not formed. MFP is still formed in the highest amount while in this case EP is formed in higher amounts than DMP. This points out that in thermal and cyclic aging different decomposition pathways are favored. Additionally the total amounts of organo(fluoro)phosphates after cyclic aging is lower than after thermal aging at $95{ }^{\circ} \mathrm{C}$ which shows that the addition of water and high temperature cause a more severe aging than cycling does.

In order to get the full picture, measurements with GC-ICP/ MS should be carried out. In the current method, only ionic substances are accessible. A GC method is able to separate the volatile nonionic substances and is therefore complementary to the IC method.

\section{Conflicts of interest}

There are no conflicts of interest to declare.

\section{Acknowledgements}

The Federal Ministry of Education and Research (BMBF) is acknowledged for funding through the project Elektrolytlabor (03X4632).

\section{Notes and references}

1 M. Armand and J. M. Tarascon, Building better batteries, Nature, 2008, 451(7179), 652-657.

2 R. Wagner, N. Preschitschek, S. Passerini, J. Leker and M. Winter, Current research trends and prospects among the various materials and designs used in lithium-based batteries, J. Appl. Electrochem., 2013, 43(5), 481-496.

3 Y. Nishi, Lithium ion secondary batteries; past 10 years and the future, J. Power Sources, 2001, 100(1-2), 101-106.

4 J. Vetter, P. Novák, M. R. Wagner, C. Veit, K. C. Möller, J. O. Besenhard, M. Winter, M. Wohlfahrt-Mehrens, C. Vogler and A. Hammouche, Ageing mechanisms in lithium-ion batteries, J. Power Sources, 2005, 147(1-2), 269281.

5 M. Broussely, P. Biensan, F. Bonhomme, P. Blanchard, S. Herreyre, K. Nechev and R. Staniewicz, Main aging mechanisms in Li ion batteries, J. Power Sources, 2005, 146(1), 90-96.

6 J. Garche, C. K. Dyer, P. T. Moseley, Z. Ogumi, D. A. Rand and B. Scrosati, Encyclopedia of electrochemical power sources, Elsevier Science, Amsterdam, Netherlands, 1st edn, 2013, p. 4538.

7 S. E. Sloop, J. K. Pugh, S. Wang, J. B. Kerr and K. Kinoshita, Chemical Reactivity of PF 5 and LiPF6 in Ethylene Carbonate/Dimethyl Carbonate Solutions, Electrochem. Solid-State Lett., 2001, 4(4), A42-A44.

8 C. L. Campion, W. Li and B. L. Lucht, Thermal decomposition of LiPF6-based electrolytes for lithium-ion batteries, J. Electrochem. Soc., 2005, 152(12), A2327-A2334.
9 G. G. Botte, R. E. White and Z. Zhang, Thermal stability of LiPF6-EC: EMC electrolyte for lithium ion batteries, $J$. Power Sources, 2001, 97-98, 570-575.

10 T. Böttcher, B. Duda, N. Kalinovich, O. Kazakova, M. Ponomarenko, K. Vlasov, M. Winter and G. V. Röschenthaler, Syntheses of novel delocalized cations and fluorinated anions, new fluorinated solvents and additives for lithium ion batteries, Prog. Solid State Chem., 2014, 42(4), 202-217.

11 T. Böttcher, N. Kalinovich, O. Kazakova, M. Ponomarenko, K. Vlasov, M. Winter and G. V. Röschenthaler, Chapter 6Novel Fluorinated Solvents and Additives for Lithium-Ion Batteries A2-Nakajima, Tsuyoshi, in Advanced FluorideBased Materials for Energy Conversion, ed. H. Groult, Elsevier, 2015, pp. 125-145.

$12 \mathrm{~K}$. Xu, Nonaqueous liquid electrolytes for lithium-based rechargeable batteries, Chem. Rev., 2004, 104(10), 43034418.

13 M. Ue, Mobility and Ionic Association of Lithium and Quaternary Ammonium Salts in Propylene Carbonate and $\gamma$-Butyrolactone, J. Electrochem. Soc., 1994, 141(12), 33363342.

14 K. Tasaki, A. Goldberg and M. Winter, On the difference in cycling behaviors of lithium-ion battery cell between the ethylene carbonate-and propylene carbonate-based electrolytes, Electrochim. Acta, 2011, 56(28), 10424-10435.

15 T. R. Jow, K. Xu, O. Borodin and U. Makoto, Electrolytes for lithium and lithium-ion batteries, Springer, Berlin, Germany, 2014, vol. 58.

$16 \mathrm{~K} . \mathrm{Xu}$, Electrolytes and interphases in Li-ion batteries and beyond, Chem. Rev., 2014, 114(23), 11503-11618.

17 M. Winter, R. Imhof, F. Joho and P. Novák, FTIR and DEMS investigations on the electroreduction of chloroethylene carbonate-based electrolyte solutions for lithium-ion cells, J. Power Sources, 1999, 81, 818-823.

18 R. W. Schmitz, P. Murmann, R. Schmitz, R. Müller, L. Krämer, J. Kasnatscheew, P. Isken, P. Niehoff, S. Nowak, G.-V. Röschenthaler, N. Ignatiev, P. Sartori, S. Passerini, M. Kunze, A. Lex-Balducci, C. Schreiner, I. Cekic-Laskovic and M. Winter, Investigations on novel electrolytes, solvents and SEI additives for use in lithium-ion batteries: systematic electrochemical characterization and detailed analysis by spectroscopic methods, Prog. Solid State Chem., 2014, 42(4), 65-84.

19 A. V. Plakhotnyk, L. Ernst and R. Schmutzler, Hydrolysis in the system LiPF 6-propylene carbonate-dimethyl carbonate- $\mathrm{H}_{2} \mathrm{O}$, J. Fluorine Chem., 2005, 126(1), 27-31.

20 S. E. Sloop, J. B. Kerr and K. Kinoshita, The role of Li-ion battery electrolyte reactivity in performance decline and self-discharge, J. Power Sources, 2003, 119, 330-337.

21 L. Terborg, S. Nowak, S. Passerini, M. Winter, U. Karst, P. R. Haddad and P. N. Nesterenko, Ion chromatographic determination of hydrolysis products of hexafluorophosphate salts in aqueous solution, Anal. Chim. Acta, 2012, 714, 121-126.

22 W. Weber, R. Wagner, B. Streipert, V. Kraft, M. Winter and S. Nowak, Ion and gas chromatography mass spectrometry 
investigations of organophosphates in lithium ion battery electrolytes by electrochemical aging at elevated cathode potentials, J. Power Sources, 2016, 306, 193-199.

23 V. Kraft, W. Weber, B. Streipert, R. Wagner, C. Schultz, M. Winter and S. Nowak, Qualitative and quantitative investigation of organophosphates in an electrochemically and thermally treated lithium hexafluorophosphate-based lithium ion battery electrolyte by a developed liquid chromatography-tandem quadrupole mass spectrometry method, RSC Adv., 2016, 6(1), 8-17.

24 V. Kraft, W. Weber, M. Grützke, M. Winter and S. Nowak, Study of decomposition products by gas chromatographymass spectrometry and ion chromatography-electrospray ionization-mass spectrometry in thermally decomposed lithium hexafluorophosphate-based lithium ion battery electrolytes, RSC Adv., 2015, 5(98), 80150-80157.

25 S. S. Zhang, A review on electrolyte additives for lithium-ion batteries, J. Power Sources, 2006, 162(2), 1379-1394.

26 B. C. Saunders and G. J. Stacey, 138. Esters Containing Phosphorus. Part IV. Diisopropyl fluorophosphonate, $J$. Chem. Soc., 1948, 695-699.

27 S. D. Silver, The toxicity of dimethyl-, diethyl-, and diisopropyl fluorophosphate vapors, J. Ind. Hyg. Toxicol., 1948, 30(5), 307311.

28 Toxicology data network, In United States National Library of Medicine.

29 H. L. Tripathi and W. L. Dewey, Comparison of the effects of diisopropylfluorophosphate, sarin, soman, and tabun on toxicity and brain acetylcholinesterase activity in mice, $J$. Toxicol. Environ. Health, 1989, 26(4), 437-446.

30 C. Schultz, V. Kraft, M. Pyschik, S. Weber, F. Schappacher, M. Winter and S. Nowak, Separation and quantification of organic electrolyte components in lithium-ion batteries via a developed HPLC method, J. Electrochem. Soc., 2015, 162(4), A629-A634.

31 L. G. Costa, Current issues in organophosphate toxicology, Clin. Chim. Acta, 2006, 366(1-2), 1-13.

32 F. M. Raushel, Chemical biology: Catalytic detoxification, Nature, 2011, 469(7330), 310-311.

33 G. Gachot, S. Grugeon, M. Armand, S. Pilard, P. Guenot, J.-M. Tarascon and S. Laruelle, Deciphering the multi-step degradation mechanisms of carbonate-based electrolyte in Li batteries, J. Power Sources, 2008, 178(1), 409-421.

34 G. Gachot, P. Ribière, D. Mathiron, S. Grugeon, M. Armand, J.-B. Leriche, S. Pilard and S. Laruelle, Gas Chromatography/ Mass Spectrometry As a Suitable Tool for the Li-Ion Battery Electrolyte Degradation Mechanisms Study, Anal. Chem., 2011, 83(2), 478-485.

35 L. Gireaud, S. Grugeon, S. Pilard, P. Guenot, J.-M. Tarascon and S. Laruelle, Mass Spectrometry Investigations on Electrolyte Degradation Products for the Development of Nanocomposite Electrodes in Lithium Ion Batteries, Anal. Chem., 2006, 78(11), 3688-3698.

36 H. Schranzhofer, J. Bugajski, H. J. Santner, C. Korepp, K. C. Möller, J. O. Besenhard, M. Winter and W. Sitte, Electrochemical impedance spectroscopy study of the SEI formation on graphite and metal electrodes, J. Power Sources, 2006, 153(2), 391-395.

37 S. Wiemers-Meyer, M. Winter and S. Nowak, Mechanistic insights into lithium ion battery electrolyte degradation a quantitative NMR study, Phys. Chem. Chem. Phys., 2016, 18(38), 26595-26601.

38 S. Wiemers-Meyer, M. Winter and S. Nowak, A Battery Cell for In Situ NMR Measurements of Liquid Electrolytes, Phys. Chem. Chem. Phys., 2017, 19, 4962-4966.

39 S. Wiemers-Meyer, M. Winter and S. Nowak, Mechanistic insights into lithium ion battery electrolyte degradationa quantitative NMR study, Phys. Chem. Chem. Phys., 2016, 18(38), 26595-26601.

40 S. Wilken, M. Treskow, J. Scheers, P. Johansson and P. Jacobsson, Initial stages of thermal decomposition of LiPF 6-based lithium ion battery electrolytes by detailed Raman and NMR spectroscopy, RSC Adv., 2013, 3(37), 16359-16364.

41 T. Kawamura, A. Kimura, M. Egashira, S. Okada and J.-I. Yamaki, Thermal stability of alkyl carbonate mixedsolvent electrolytes for lithium ion cells, J. Power Sources, 2002, 104(2), 260-264.

42 C. L. Campion, W. Li, W. B. Euler, B. L. Lucht, B. Ravdel, J. F. DiCarlo, R. Gitzendanner and K. M. Abraham, Suppression of Toxic Compounds Produced in the Decomposition of Lithium-Ion Battery Electrolytes, Electrochem. Solid-State Lett., 2004, 7(7), A194-A197.

43 L. Terborg, S. Weber, F. Blaske, S. Passerini, M. Winter, U. Karst and S. Nowak, Investigation of thermal aging and hydrolysis mechanisms in commercial lithium ion battery electrolyte, J. Power Sources, 2013, 242, 832-837.

44 C. Schultz, S. Vedder, M. Winter and S. Nowak, Qualitative Investigation of the Decomposition of Organic Solvent Based Lithium Ion Battery Electrolytes with LC-IT-TOF-MS, Anal. Chem., 2016, 88(22), 11160-11168.

45 M. Tochihara, H. Nara, D. Mukoyama, T. Yokoshima, T. Momma and T. Osaka, Liquid ChromatographyQuadruple Time of Flight Mass Spectrometry Analysis of Products in Degraded Lithium-Ion Batteries, J. Electrochem. Soc., 2015, 162(10), A2008-A2015.

46 S. Takeda, W. Morimura, Y.-H. Liu, T. Sakai and Y. Saito, Identification and formation mechanism of individual degradation products in lithium-ion batteries studied by liquid chromatography/electrospray ionization mass spectrometry and atmospheric solid analysis probe mass spectrometry, Rapid Commun. Mass Spectrom., 2016, 30(15), 1754-1762.

47 W. Weber, V. Kraft, M. Grützke, R. Wagner, M. Winter and S. Nowak, Identification of alkylated phosphates by gas chromatography-mass spectrometric investigations with different ionization principles of a thermally aged commercial lithium ion battery electrolyte, J. Chromatogr. A, 2015, 1394, 128-136.

48 V. Kraft, M. Grützke, W. Weber, M. Winter and S. Nowak, Ion chromatography electrospray ionization mass spectrometry method development and investigation of lithium hexafluorophosphate-based organic electrolytes and their 
thermal decomposition products, J. Chromatogr. A, 2014, 1354, 92-100.

49 V. Kraft, M. Grützke, W. Weber, J. Menzel, S. WiemersMeyer, M. Winter and S. Nowak, Two-dimensional ion chromatography for the separation of ionic organophosphates generated in thermally decomposed lithium hexafluorophosphate-based lithium ion battery electrolytes, J. Chromatogr. A, 2015, 1409, 201-209.

50 S. F. Lux, J. Chevalier, I. T. Lucas and R. Kostecki, HF Formation in LiPF6-Based Organic Carbonate Electrolytes, ECS Electrochem. Lett., 2013, 2(12), A121-A123.

51 S. F. Lux, I. T. Lucas, E. Pollak, S. Passerini, M. Winter and R. Kostecki, The mechanism of HF formation in LiPF6 based organic carbonate electrolytes, Electrochem. Commun., 2012, 14(1), 47-50.

52 A. Wilken, V. Kraft, S. Girod, M. Winter and S. Nowak, A fluoride-selective electrode (Fse) for the quantification of fluoride in lithium-ion battery (Lib) electrolytes, Anal. Methods, 2016, 8(38), 6932-6940.

53 M. Pyschik, M. Klein-Hitpaß, S. Girod, M. Winter and S. Nowak, Capillary electrophoresis with contactless conductivity detection for the quantification of fluoride in lithium ion battery electrolytes and in ionic liquidsa comparison to the results gained with a fluoride ionselective electrode, Electrophoresis, 2017, 38(3-4), 533-539.

54 L. Terborg, S. Weber, F. Blaske, S. Passerini, M. Winter, U. Karst and S. Nowak, Investigation of thermal aging and hydrolysis mechanisms in commercial lithium ion battery electrolyte, J. Power Sources, 2013, 242, 832-837.

55 C. Schultz, S. Vedder, B. Streipert, M. Winter and S. Nowak, Quantitative investigation of the decomposition of organic lithium ion battery electrolytes with LC-MS/MS, RSC Adv., 2017, 7(45), 27853-27862. 